\title{
Can a simple structural time series model beat the random walk?
}

\author{
Yip Chee Yin, Quah Soon Hoe, Anton Abdulbasah Kamil*, Zainudin Arsad
}

School of Mathematical Sciences, Universiti Sains Malaysia, 11800 USM, Penang, Malaysia

*To whom correspondence should be addressed. E-mail: anton@cs.usm.my

Received 25 July 2006

http://dx.doi.org/10.11113/mjfas.v2n1-2.18

\begin{abstract}
This paper tries to address the question that if the long run PPP holds, then there should exist a structural model which can outperform the random walk in out of sample forecasting. We propose an ARFIMA based model with log of the independent variable as an explanatory variable and make a comparison study of this structural model with the benchmark random walk model. Then, we compare our results with that as obtained by Engel and Hamilton, and by Clarida, Sarno, Taylor and Valente. We present the standard ARFIMA model and show how can make an extension of it so that it becomes a variant of ARFIMA and name it as YQ-ARFIMA, then construct a bivariate model relating the dependent variable $y_{t}$ and $\ln y_{t}$, and with that, perform an impulse response function analysis of the predictive ability of $l n y_{t}$. We also transform the YQ-ARFIMA into a moving average representation, and thereafter perform the impulse response function analysis again, then make a comparison study between the standard ARFIMA and the YQARFIMA by comparing the out of sample forecasting ability of each one of them with the benchmark random walk model. After that, compare the performance of YQ-ARFIMA with that of the Markov switching model put forward by Engel and Hamilton, and the MSIH(3)-VECM as put forward by CSTV. Last, we test the robustness of the YQ-ARFIMA by fitting it into different exchange rate series spanning the five continents of the globe, then, test the consistency of the forecast by YQ-ARFIMA by a cointegration technique. By using the loss functions RMSE and MAPE, cointegration consistency in forecasts and impulse response function analysis, we have shown beyond doubt that theYQ-ARFIMA model is very much superior in forecasting ability.
\end{abstract}

| Nominal exchange rates | Purchasing power parity | Forecasting performance | Impulse response function | RMSE loss function | MAPE loss function | ARFIMA process | Cointegration consistent forecast | The explanatory power of the log of a variable |

\section{Introduction}

Exchange rate has been one of the most important macroeconomic variables in determining the economic well being of a country. With a good knowledge of exchange rate, we can determine the degree of misalignment of the nominal exchange rate and thereby formulate the appropriate policy response. We also can set the exchange rate parities with accuracy. Furthermore, we can use the knowledge of exchange rate to compare national income 
levels internationally. Researches on exchange rate are mostly based on the purchasing power parity (PPP) hypothesis, which states that national price levels should be equal when expressed in a common currency. This definition simply implies that over the long run exchange rate will achieve an equilibrium level. We refer to this long run equilibrium level as mean reverting or parity reversion. This parity reversion behavior has been under intense research for the past two decades or so. In the 1980s, Meese and Singleton (1982) report that the random walk hypothesis is supported by the exchange rate data based on formal unit root tests. Furthermore, more direct evidence has been presented by Meese and Rofoff (1983) using out of sample forecasting experiments. More recently, favorable evidence has been unveiled in support of long run PPP among the major industrialized economies for the recent float. Papers published by Cheung and Lai, 1994, 1998.

This paper tries to address one key question: If the long run PPP holds, then there should exist a structural model which can outperform the random walk in out of sample forecasting. Can we find this structural model? This challenge was taken up by the econometricians. The prominent ones are listed below:

1. Schinasi and Swamy (1989) use a Kalman filter maximum likelihood estimation technique to estimate time varying parameter models which are found to outperform the random walk model of exchange rate for certain time periods and currencies.

2. Engel and Hamilton (1990) applies the Markov switching model to dollar exchange rate data and show that the model generates better forecast than a random walk.

3. Clarida, Sarno, Taylor and Valente (CSTV) (2003) proposed a three regime Markov switching intercept heteroskedatic VECM (MSIH-VECM) model, which is a nonlinear model. They found that this model gives very much more accurate forecasts than a random walk.

In this paper, we propose an ARFIMA based model with log of the independent variable as an explanatory variable. We make a comparison study of this structural model with the benchmark random walk model. Then, we compare our results with that as obtained by Engel and Hamilton, and by Clarida, Sarno, Taylor and Valente.

\section{YQ-ARFIMA model}

Fractionally integrated processes as discussed by Granger and Joyeux (1980) has the property to display mean reversion behavior, and that long memory process is a special case for it.

A fractionally integrated process can be represented by

$$
B(L)(1-L)^{d} y_{t}=A(L) u_{t}
$$

where $B(L)=1-B_{1} L-\ldots-B_{p} L^{p}$ and $A(L)=1+A_{1} L+\ldots+A_{q} L^{q}$. We refer equation (2.1) as the standard ARFIMA model. We can introduce an explanatory term in the form of logarithm into equation (2.1). Thus, after the introduction of the explanatory variable, we have a modified version of (2.1).

$$
B(L)(1-L)^{d}\left[y_{t}-\ln y_{t}\right]=A(L) u_{t}
$$

All the roots of $B(L)$ and $A(L)$ lie outside the unit circle so that the ARMA framework is stationary and inverting. While $u_{t}$ is an iid $\left(0, \sigma^{2}\right)$ and the fractional differencing operator is given by

$$
(1-L)^{d}=\sum_{k=0}^{\infty} \Gamma(k-d) L^{k} /[\Gamma(k+1) \Gamma(-d)]
$$


where $\Gamma($.$) is referred to as the autoregressive fractionally integrated moving average (YQ-ARFIMA) model,$ and its representation in symbol is like this: YQ-ARFIMA(p,d,q). Equation (2.2) is obtained after a lengthy literature review of the recent development in exchange rate modeling especially with respect to nonlinear exchange rate modeling.

There is increasingly strong evidence of nonlinearities of one sort or another in exchange rate movements. Consequently, Engel and Hamilton used a Markov switching model to characterize exchange rate behavior. This was followed by Clarida, Sarno, Taylor and Valente (CSTV) (2003) rather successfully when they tracked the exchange rate by using a fairly general three-regime Markov switching vector equilibrium correction model (MSVECM). The successes of these nonlinear models, and the finding by using TAR model that allows for a transactions costs band within which no adjustment takes place so that deviations from PPP may exhibit unit root behavior while outside of the band the process switches abruptly to become stationary autoregressive, motivate us to look for a mixture of linear and nonlinear framework to model the exchange rate. ARFIMA process is based on linear modeling of autoregressive and moving average processes. Log of a variable is the simplest of a nonlinear function. Thus, it is only logical to introduce it into the standard ARFIMA model to see if it performs well or not.

The followings are the results of an experiment to determine the best specification of the standard ARFIMA and the YQ-ARFIMA for the case of exchange rate, British pound per US dollar (Britpus), and thereafter, we compare the predictive ability of the standard ARFIMA and the YQ-ARFIMA by using the loss functions RMSE and MAPE for comparison.

Table 1(a)- Model specifications of the standard ARFIMA and the YQ-ARFIMA

\begin{tabular}{|c|c|c|c|c|c|}
\hline Models & Regressors & log-likelihood & $\mathrm{SC}$ & HQ & AIC \\
\hline $\operatorname{Arfima}(2, \mathrm{~d}, 1)$ & Const.LBritpus,trend & 28144.752 & -11.778 & -11.785 & -11.788 \\
\hline $\operatorname{Arfima}(2, \mathrm{~d}, 1)$ & Const.LBritpus,LBritpus_1 & 28140.021 & -11.779 & -11.785 & -11.788 \\
\hline $\operatorname{Arfima}(3, \mathrm{~d}, 2)$ & Const.LBripus, Trend & 28143.596 & -11.777 & -11.785 & -11.789 \\
\hline $\operatorname{Arfima}(4, \mathrm{~d}, 4)$ & Const.LBritpus & 28172.999 & -11.786 & -11.795 & -11.801 \\
\hline $\operatorname{Arfima}(4, \mathrm{~d}, 3)$ & Const.LBritpus & 28152.812 & -11.779 & -11.788 & -11.793 \\
\hline $\operatorname{Arfima}(4, \mathrm{~d}, 4)$ & Const. & 19331.825 & -8.0827 & -8.0915 & -8.0963 \\
\hline $\operatorname{Arfima}(2, \mathrm{~d}, 2)$ & Const. & 19335.377 & -8.0896 & -8.0949 & -8.0978 \\
\hline $\operatorname{Arfima}(2, \mathrm{~d}, 1)$ & Const. & 19334.919 & -8.0912 & -8.0956 & -8.0980 \\
\hline $\operatorname{Arfima}(2, \mathrm{~d}, 2)$ & Const.LBritpus & 28129.722 & -11.772 & -11.778 & -11.782 \\
\hline $\operatorname{Arfima}(2, \mathrm{~d}, 1)$ & Const.LBritpus & 28142.667 & -11.779 & -11.785 & -11.787 \\
\hline $\operatorname{Arfima}(3, \mathrm{~d}, 3)$ & Const. & 19344.036 & -8.0897 & -8.0968 & -8.1006 \\
\hline $\operatorname{Arfima}(3, \mathrm{~d}, 2)$ & Const. & 19343.212 & -8.0911 & -8.0973 & -8.1006 \\
\hline $\operatorname{Arfima}(3, \mathrm{~d}, 2)$ & Const.LBritpus & 28144.145 & -11.776 & -11.784 & -11.787 \\
\hline
\end{tabular}


Table 1(b) -The best 5 specifications of the model

The best 5 specifications in terms of position are:

$\begin{array}{lllllll}1 & \text { Arfima(4,d,4) } & \text { Const.LBritpus } & 28172.999 & -11.786 & -11.795 & -11.801 \\ 2 & \text { Arfima(4,d,3) } & \text { Const.LBritpus } & 28152.812 & -11.779 & -11.788 & -11.793 \\ 3 & \text { Arfima(2,d,1) } & \text { Const.LBritpus,trend } & 28144.752 & -11.778 & -11.785 & -11.788 \\ 4 & \text { Arfima(3,d,2) } & \text { Const.LBritpus } & 28144.145 & -11.776 & -11.784 & -11.787 \\ 5 & \text { Arfima(2,d,1) } & \text { Const.LBritpus } & 28142.667 & -11.779 & -11.785 & -11.787\end{array}$

Table 2 - Comparison of the predictive ability of the best 5 ARFMA specifications

\begin{tabular}{|c|c|c|c|c|c|c|c|}
\hline Specification & Models & Regressors & $\mathrm{SC}$ & HQ & AIC & RMSE & MAPE \\
\hline 1 & $\operatorname{Arfima}(4, \mathrm{~d}, 4)$ & Const,.LBritpus & -11.786 & -11.795 & -11.801 & 0.00023400 & 0.031395 \\
\hline 2 & $\operatorname{Arfima}(4, \mathrm{~d}, 3)$ & Const.,LBritpus & -11.779 & -11.788 & -11.793 & 0.00023723 & 0.032085 \\
\hline 3 & $\operatorname{Arfima}(2, \mathrm{~d}, 1)$ & $\begin{array}{l}\text { Const,LBritpus, } \\
\text { trend }\end{array}$ & -11.778 & -11.785 & -11.788 & 0.00009544 & 0.012038 \\
\hline 4 & $\operatorname{Arfima}(3, \mathrm{~d}, 2)$ & Const,LBritpus & -11.776 & -11.784 & -11.787 & 0.00023439 & 0.031195 \\
\hline 5 & $\operatorname{Arfima}(2, \mathrm{~d}, 1)$ & Const,LBritpus & -11.779 & -11.785 & -11.787 & 0.00022692 & 0.029991 \\
\hline
\end{tabular}

The best model for prediction is $\operatorname{ARFIMA}(2, \mathrm{~d}, 1)$ with constant, LBritpus and trend as regressors

Note: Const stands for Constant

Table 2 shows that ARFIMA(2,d,1) with LBritpus and constant as regressors is the best specification for ARFIMA. Furthermore when trend is added in as an extra regressor, the RMSE and MAPE become very much better than the one without trend as an extra regressor. However, the model is not as stable as the one without trend as regressor. Moreover, with trend as an extra regressor, we found that some of the parameter values are not acceptable because they return a value of $t$ less than 2 . Hence, we take ARFIMA $(2, d, 1)$ with constant and LBritpus as the best specification for the exchange rate, Britpus. For other exchange rates, the values of the ARFIMA parameters may change, but all the while, we fix the regressor as log of the exchange rate series. We name this specification as YQ-ARFIMA model. 


\section{Impulse response function analysis}

Impulse response function has been used to determine the effectiveness the predictive ability of the model. It is based on the amount of changes that can be induced on the dependent variable by one unit change in the explanatory variable. We perform the impulse response function analysis by using the bivariate VAR model.

\subsection{A bivariate VAR model}

Our main interest in the formulation of a cointegrated VAR model is to measure the relative performance of the respective explanatory variables in forecasting the movements of the dependent variables. Thus, we have the following model after giving all the variables concerned a one or two lagged component. The model is given by

$$
\begin{aligned}
& y_{t}=\alpha_{0}+\alpha_{1} y_{t-1}+\alpha_{2} \ln y_{t}+\alpha_{3} \ln y_{t-1} \\
& \ln y_{t}=\beta_{0}+\beta_{1} \ln y_{t-1}+\beta_{2} y_{t}+\beta_{3} y_{t-1}
\end{aligned}
$$

We run the experiment as described by equation (3.1) for the case of exchange rates from Australia, Malaysia, South Africa, Britain, European Union, Canada, Mexico, and lastly Brazil. For each of these exchange rates, we started with 3 lags for both the dependent and explanatory variables. We perform a multivariate dynamic modeling, which involves $\mathrm{F}$ tests to test the significant level of all the variables involved. By this procedure, we are able to determine the correct number of lags involved in the bivariate modeling. After that, we will conduct a cointegrated VAR investigation of the exchange rates if the number of lags is the same for both of the variables. The relevant experimental results are graphed as impulse response function graphs and cumulated impulse response graphs. Four graphs are shown for each of the exchange rate: two for impulse response and the two, for cumulated impulse response. Figure 1 to 8 show the eight sets of graphs, which are obtained by using procedure as explained.

For the Australian dollar:

Figure 1(a) shows that the effect of the Log of the Australian dollar (Laus) rises sharply initially, and then achieve a steady influence on the Australian dollar. The cumulative effect of Laus is shown in Figure 1(c), where this effect is linear with a growth rate of about 7 . This linearity of the growth rate contributes greatly to the accuracy of the forecasts. As for the case of feedback, that is simultaneous bias of the forecast, we can deduce from Figure 1(b), where the effect drops sharply and after which, it achieves a very small steady value of less than 0.25 . The cumulative effect of Australian dollar on $\log$ of the Australian dollar is dropping at rate of 1.7 as shown in Figure 1(d). Thus, we can conclude that there is practically no effective simultaneous bias in the forecast with $\log$ of the exchange rate as an explanatory variable. A similar situation occurs for the Malaysian ringgit as shown in Figure 2(a), 2(b), 2(c) and 2(d). As for the exchange rate from United Kingdom (UK), we find that the decrease of the effect of British pound on log of the British pound is dropping rather sharper than the cases for Malaysia and Australia. This also indicates that there is negligible simultaneous equation bias in the forecast using log of the British pound as an explanatory regressors.

Figure 4 shows the impulse response functions graphs and the cumulative impulse response functions graphs for Euro. Notice that the first graph, Figure 4(a) shows the effect of Leuro in helping to forecast Euro is increasing as the time span increases. However, the feedback is also true that is the effect of Euro in helping to forecast Leuro is also increasing as the time span increases. Thus, there is simultaneous bias in the forecast of Euro by Leuro. 
This indicates that to use Leuro as an explanatory variable in forecasting Euro is not suitable as there is simultaneous bias in the forecast.

This problem of simultaneous bias in the forecast is also occurring in the exchange rate for South Africa as shown in Figure 5(a) and Figure 5(b). As for Canada dollar, the problem of simultaneous bias becomes worse because it seems the exchange rate series does better in helping to forecast log of the exchange rate.

However, for case of Mexico, Lmexico does help a lot in forecasting the exchange rate series, Mexico Pesos as shown in Figure 7(a) and Figure 7(c). For the Mexico Pesos, there is no appreciable simultaneous bias as shown in Figure 7(b) and Figure 7(d).

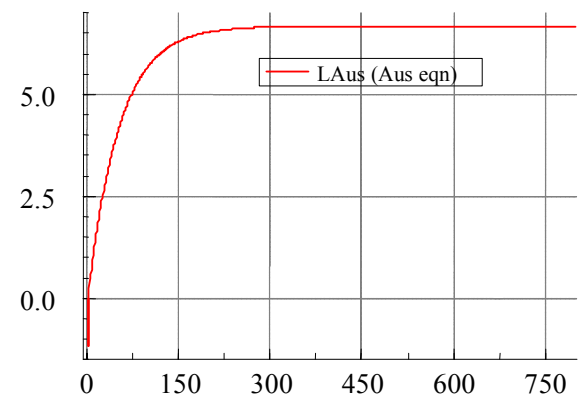

Figure 1(a)- The effect of Log Aus

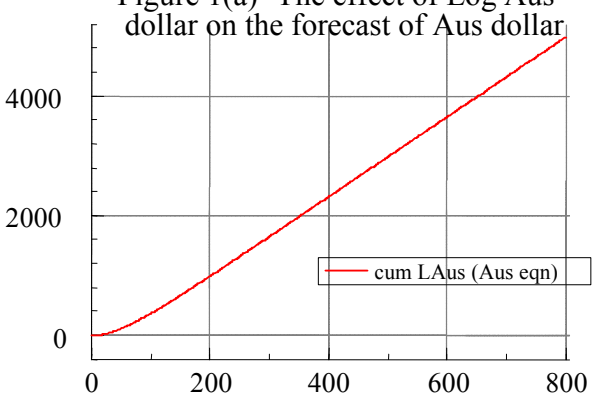

Figure 1(c)- The cumulated effect of Log Aus dollar on the forecast of Aus dollar

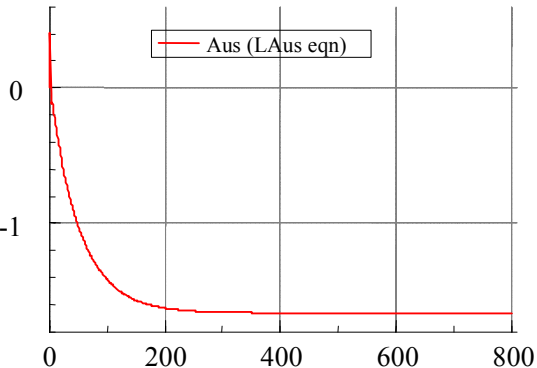

Figure 1(b) - The effect of Aus dollar on the forecast of $\log$ Aus dollar

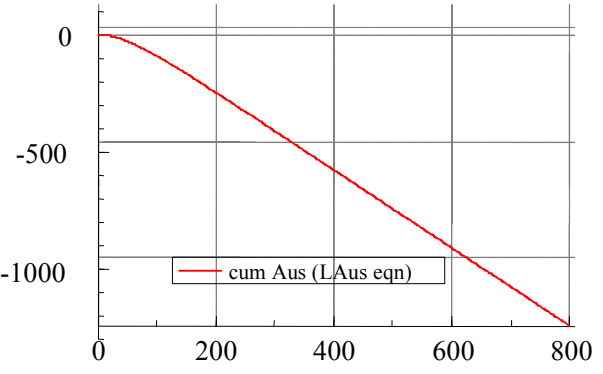

Figure 1(d)- The cumulated effect of Aus dollar on the forecast of Log Aus dollar

Figure 1 - Impulse response and cumulative impulse response graphs for Australian (Aus) dollar. 

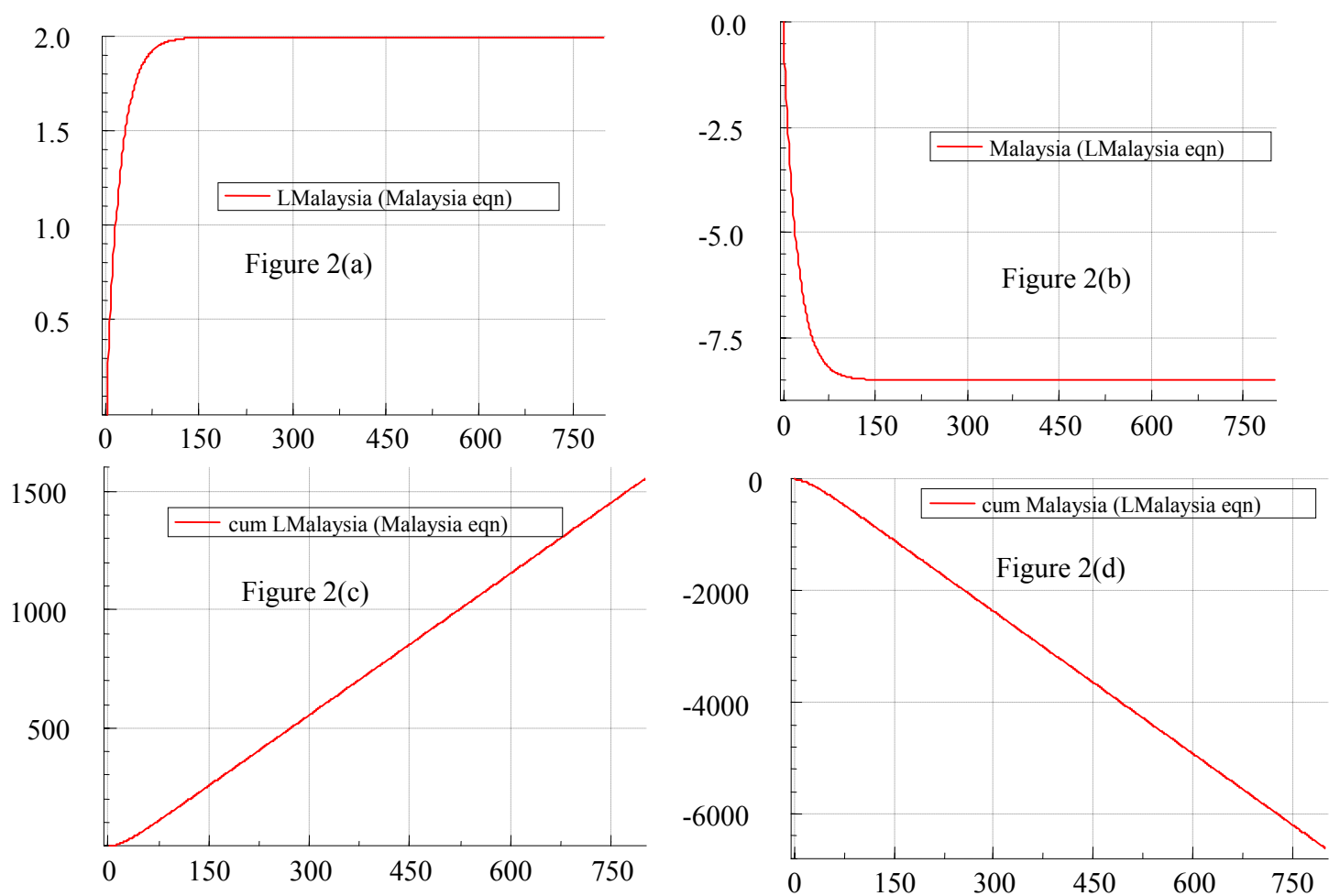

Figure 2 - Impulse response and cumulative response graphs for Malaysian Ringgit. 


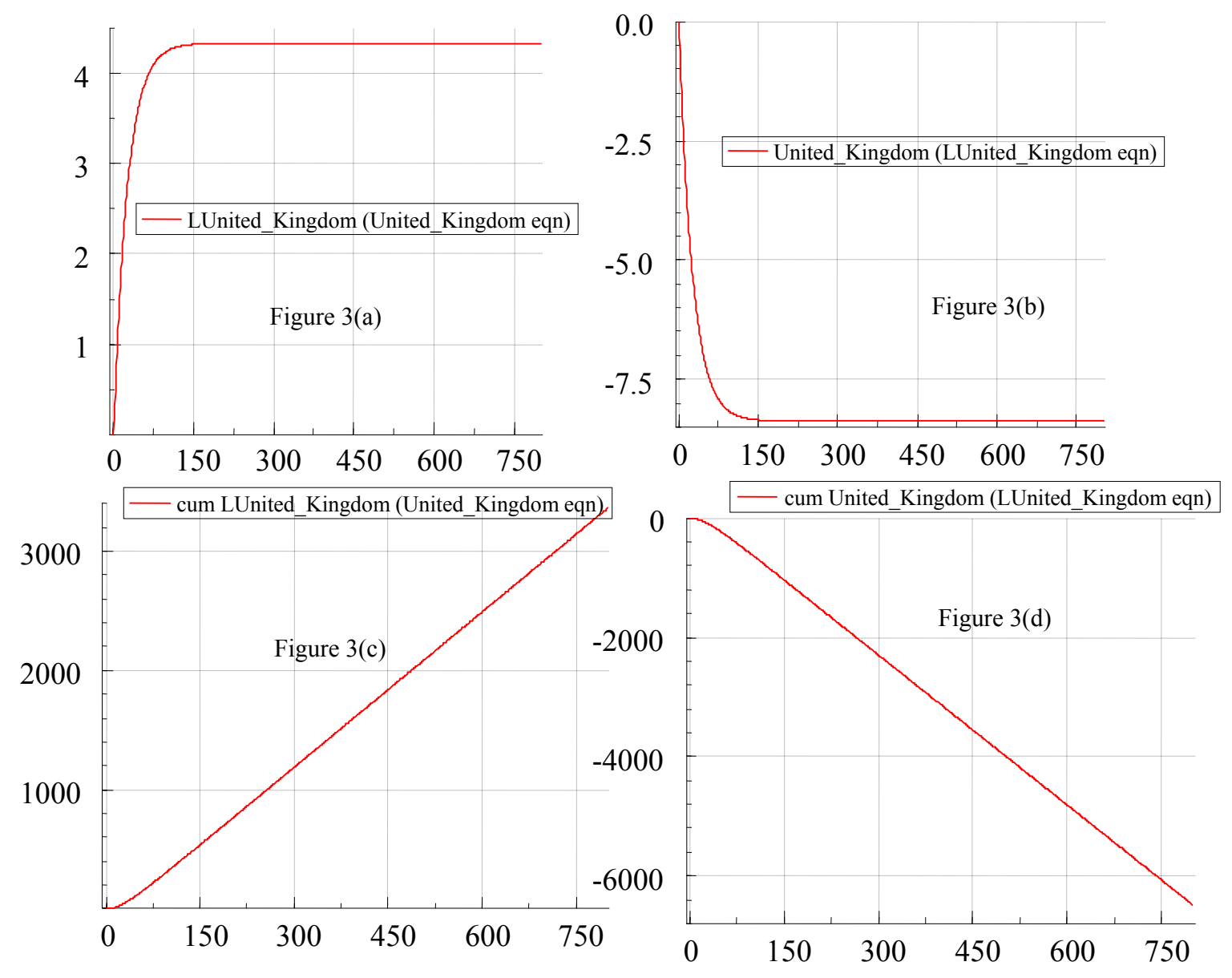

Figure 3 - Impulse response and cumulative impulse response for UK pound. 

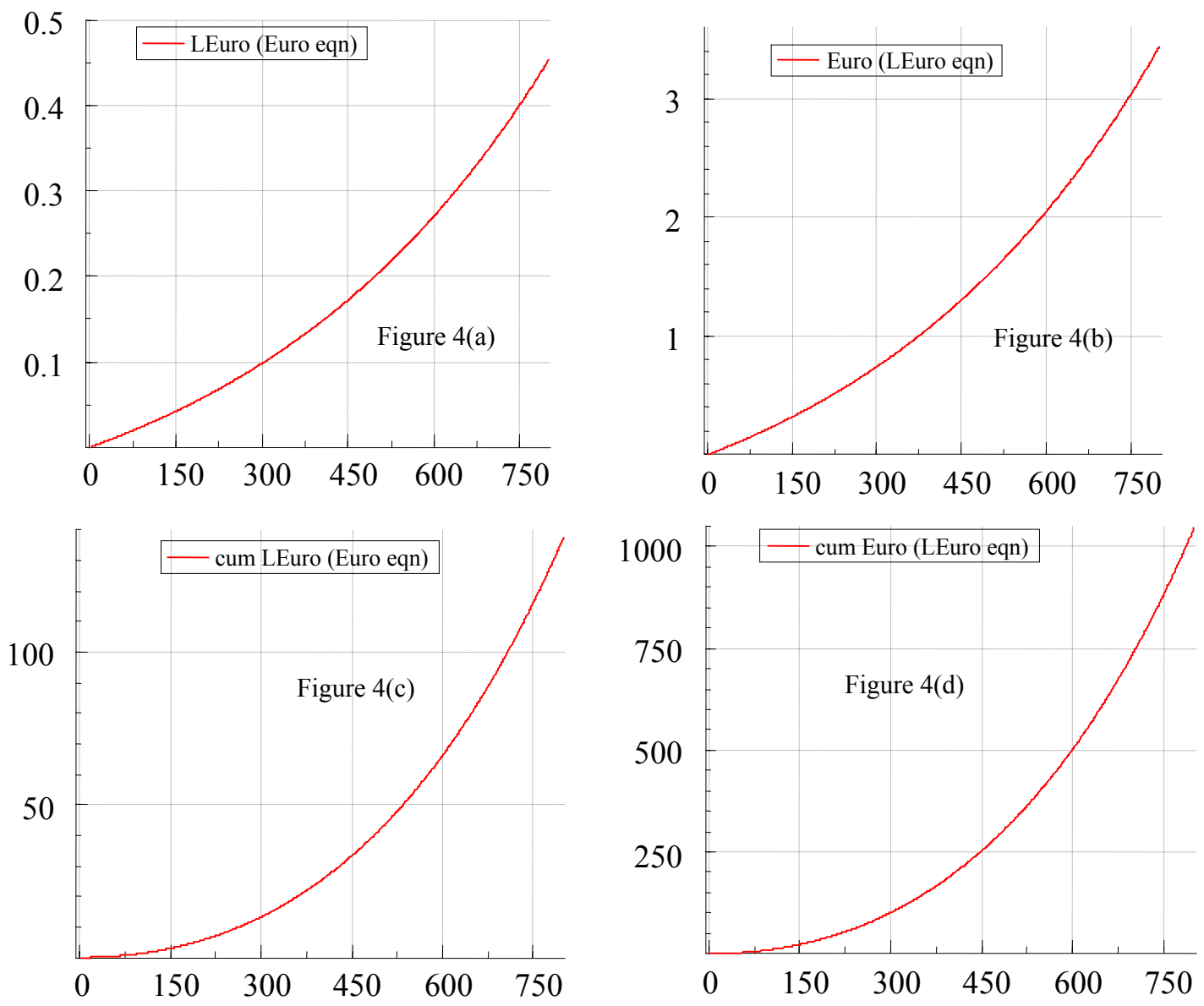

Figure 4 - Impulse response and cumulative impulse response for euro. 

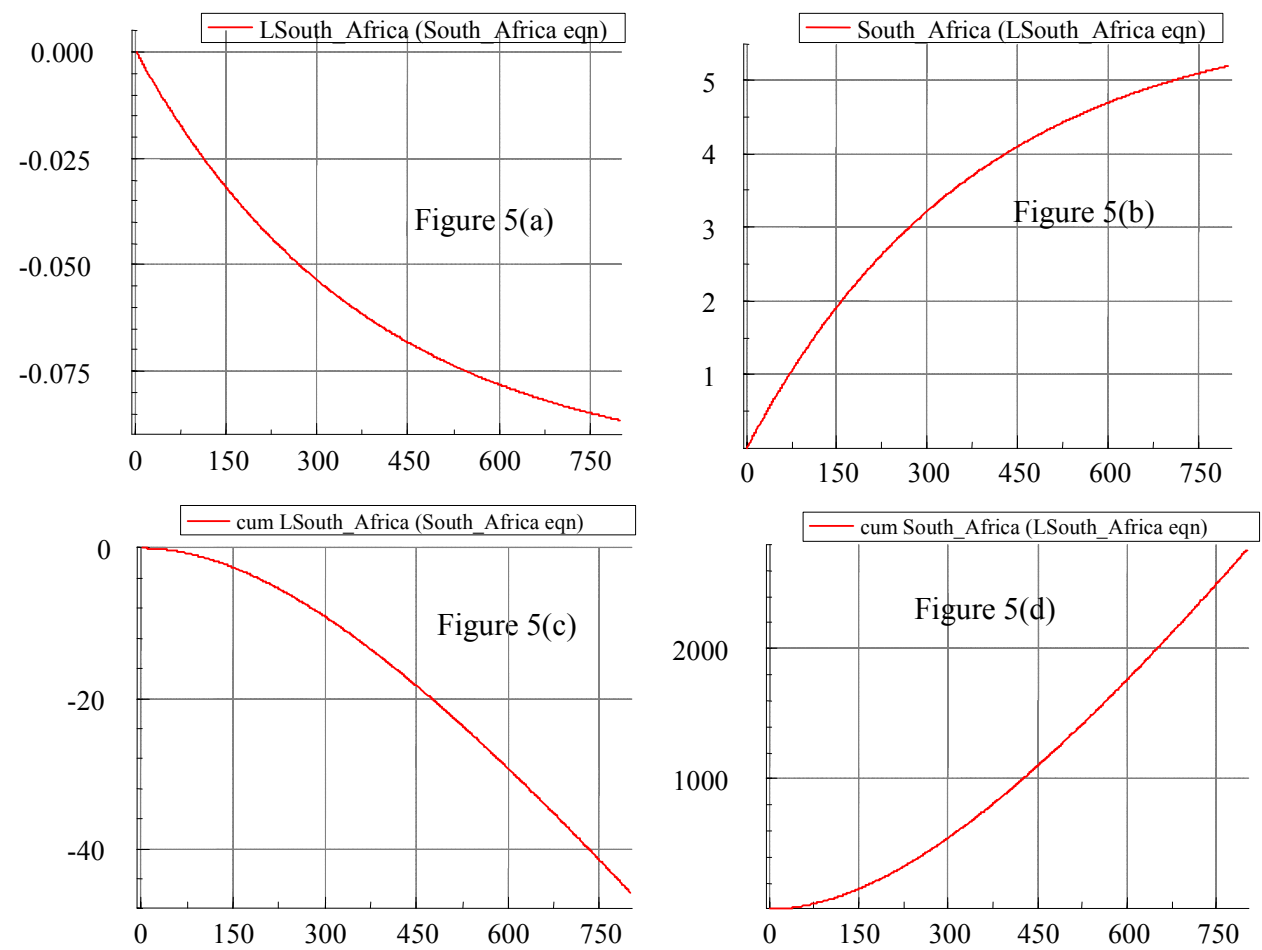

Figure 5 - Impulse response and cumulative impulse response for South Africa Rand. 

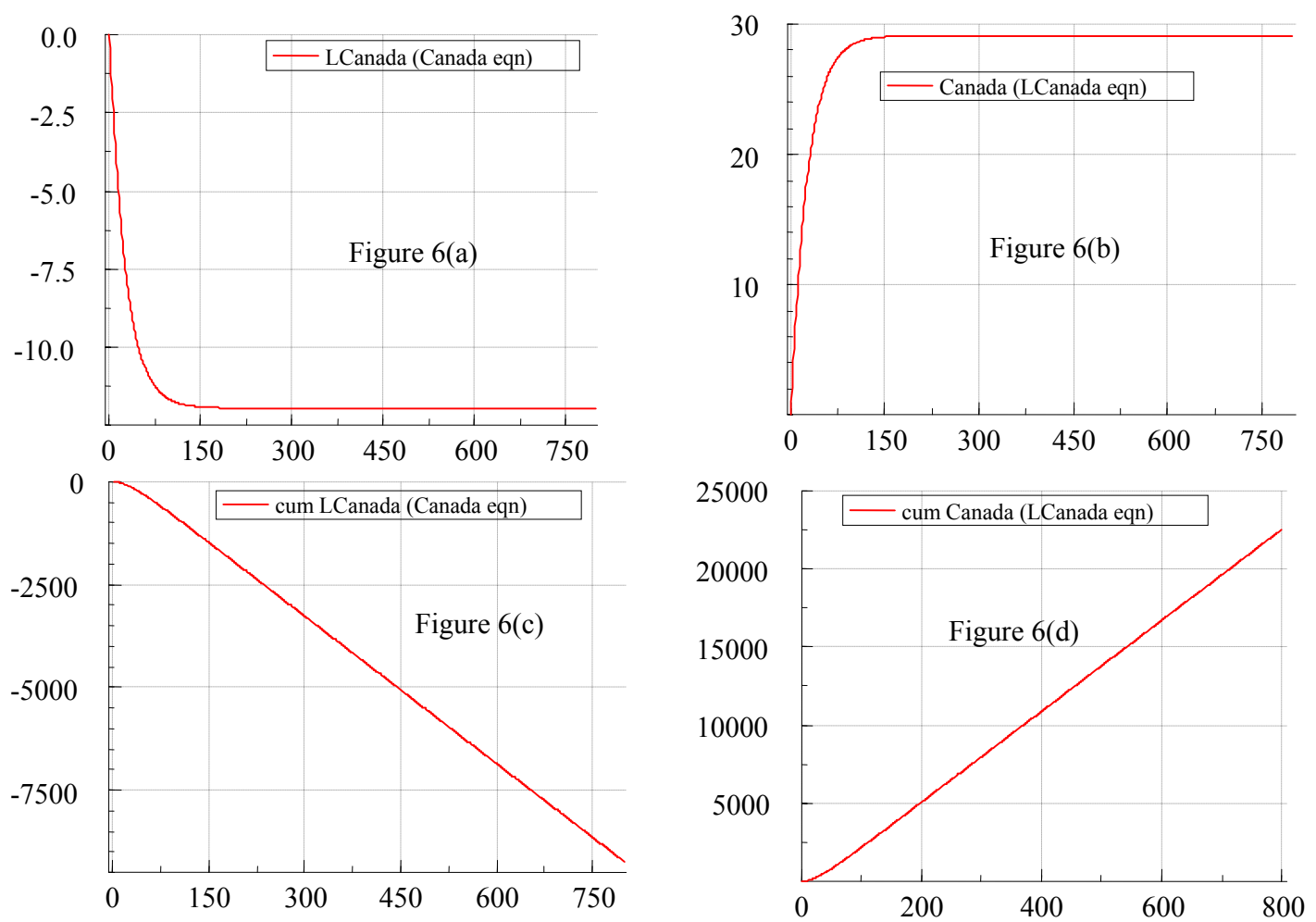

Figure 6 - Impulse response and cumulative response graphs for Canadian dollar. 

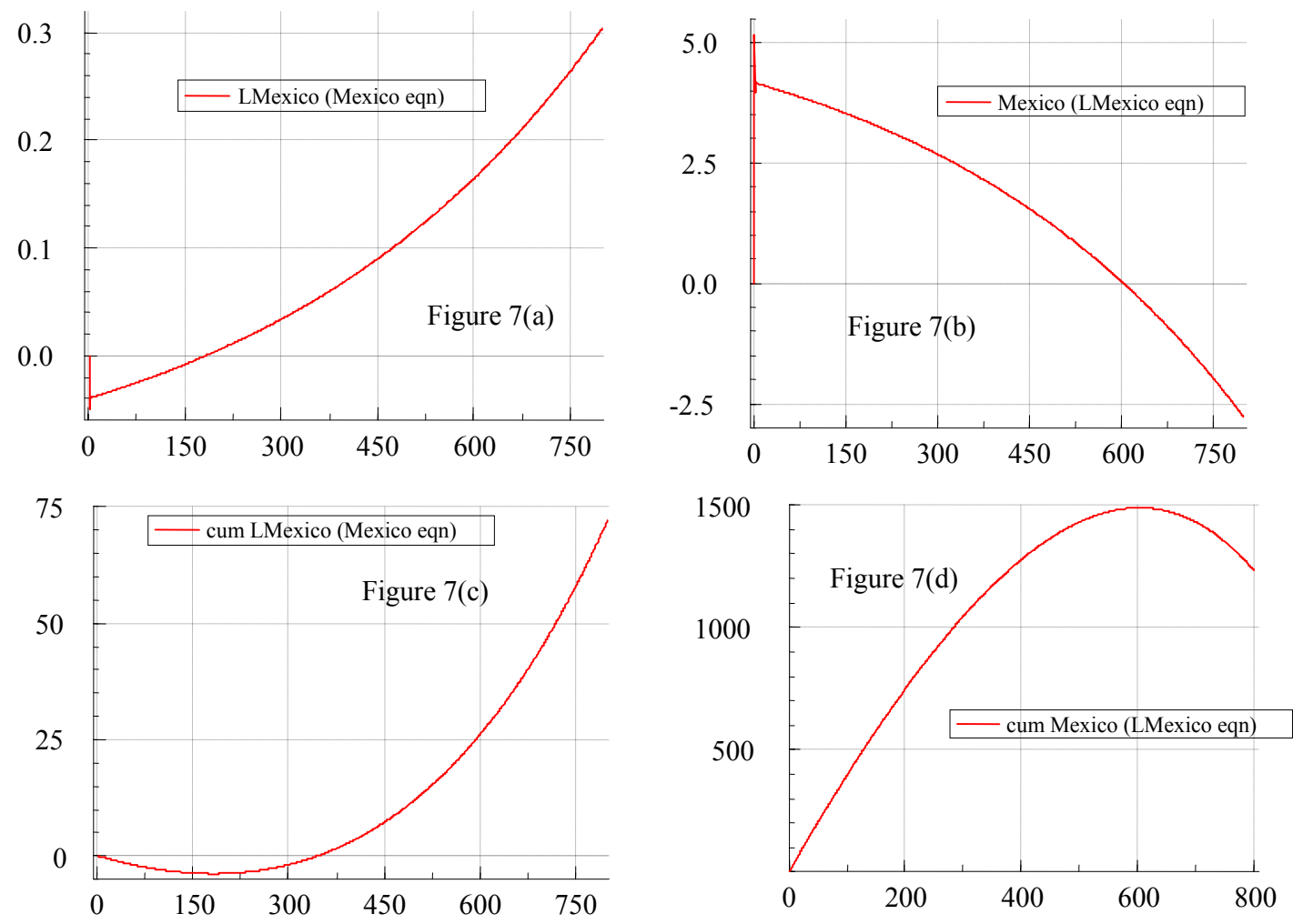

Figure 7 - Impulse response and cumulative response graphs for Mexico Pesos. 

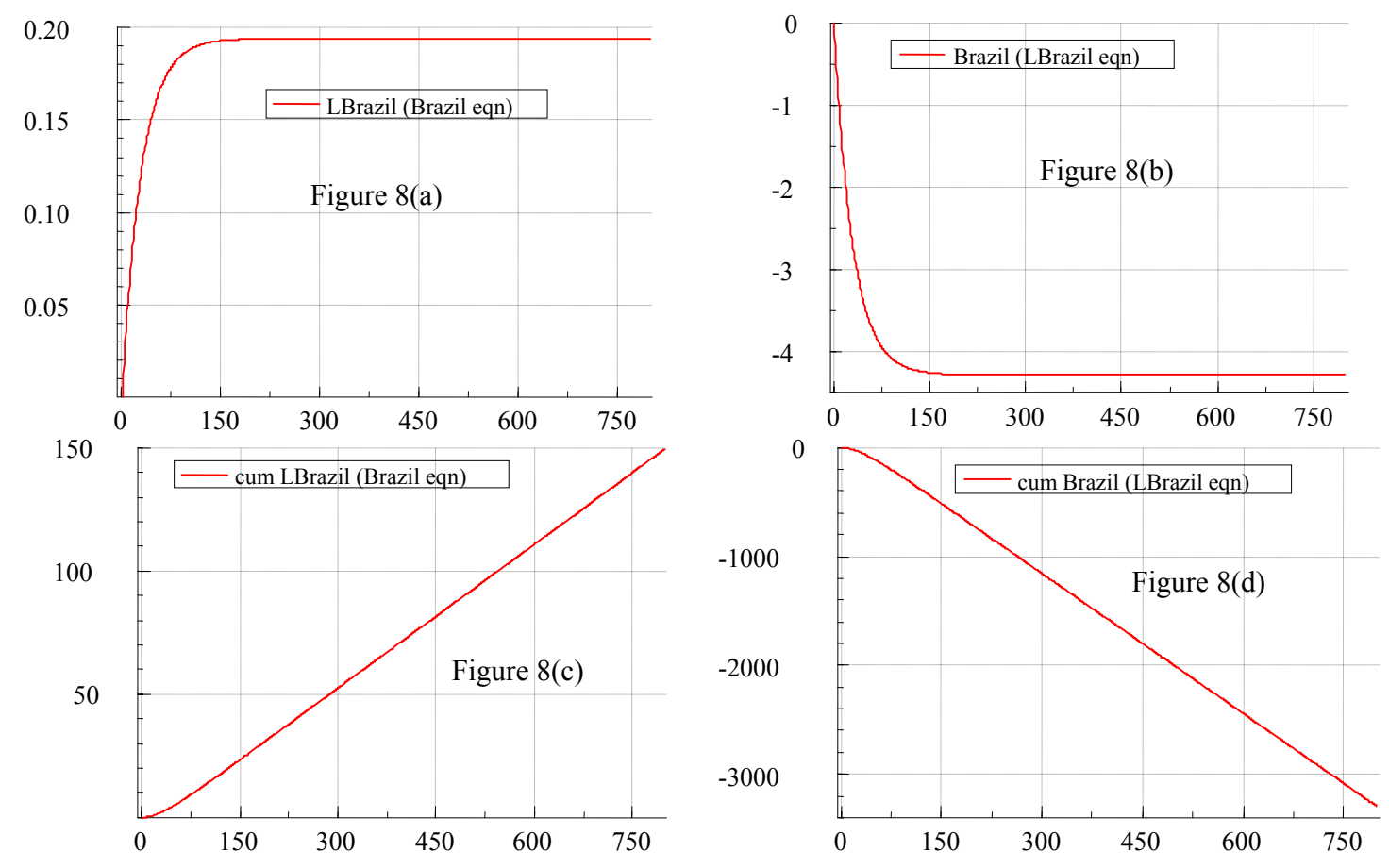

Figure 8 - Impulse response and cumulative impulse response graphs for Brazilian Real.

Lastly, we found that Lbrazil performs soundly as an explanatory variable in forecasting Brazilian Real in Figure 8. The situation is very similar to that in Malaysia. Thus, through the impulse response function analysis, we have shown that log of the exchange rate series can have great effect in helping to forecast the exchange rates in Australia, Malaysia, Britain, Mexico and Brazil. As for exchange rates in Canada, European Union and South Africa, we cannot use log of the exchange rates to help in the forecast of the exchange rates.

\section{Comparing YQ-ARFIMA, ARFIMA with Random Walk}

We have chosen the random walk without drift as the benchmark model for comparison. We perform out of sample forecasting for comparison only because out of sample forecasting has the advantage of lessen parameters instability that causes problems for genuine forecasts. We use data sets from Malaysia, Thailand, Singapore, Hong Kong, China, Japan, Australia, Denmark, Switzerland, Canada, Mexico, Brazil, European Union, South Africa and Britain for the experiments. Table 3 shows the results or the experiments. For each exchange rate, we use ARFIMA(1,d,0), $\operatorname{ARFIMA}(1, \mathrm{~d}, 1), \operatorname{ARFIMA}(2, \mathrm{~d}, 1)$ and $\operatorname{ARFIMA}(4, \mathrm{~d}, 4)$ to model the series and obtain the RMSE and MAPE for out of sample forecasting. After that, we select a common specification for the estimation of the values of RMSE and MAPE for all the 15 exchange rate series. We repeat the same procedure for YQARFIMA and the Random walk model. For comparison purpose, we use the random walk model as the benchmark model. We divide the RMSE values from the random walk model by the RMSE values from the 
ARFIMA model and the YQ-ARFIMA model. We repeat the same calculation for the MAPE values. Through rigorous investigation by doing experiments, we found that $\operatorname{ARFIMA}(1, \mathrm{~d}, 0)$ is the best specification for all the exchange rate series. Thus, we use the ARFIMA $(1, \mathrm{~d}, 0)$ specification for the standard ARFIMA and the YQARFIMA.

Table 3 - Comparing the 8 period forecasting ability of ARFIMA, YQ-ARFIMA and Random Walk in terms of RMSE values for all the 15 exchange rate series.

\begin{tabular}{|c|c|c|c|c|c|c|}
\hline $\begin{array}{l}\text { Name of } \\
\text { the exchange } \\
\text { rate }\end{array}$ & $\begin{array}{l}\text { ARFIMA } \\
\text { (P) }\end{array}$ & $\begin{array}{l}\text { YQ-ARFIMA } \\
\text { (Q) }\end{array}$ & $\begin{array}{l}\text { R.W } \\
\text { (R) }\end{array}$ & $\mathrm{R} / \mathrm{P}$ & $\mathrm{R} / \mathrm{Q}$ & $\mathrm{P} / \mathrm{Q}$ \\
\hline Aus dollar & 0.0030684 & 0.000066456 & 0.0032251 & 1.05 & 48.53 & 46.17 \\
\hline Mal ringgit & 0.0016198 & 0.000052401 & 0.0027042 & 1.67 & 51.61 & 30.91 \\
\hline Thai bath & 0.29459 & 0.0029306 & 0.29234 & 0.99 & 99.75 & 100.52 \\
\hline Sin dollar & 0.0084508 & 0.00034379 & 0.0082749 & 0.98 & 24.07 & 24.58 \\
\hline Jap yen & 0.37923 & 0.023582 & 0.4016 & 1.06 & 17.03 & 16.08 \\
\hline UK pound & 0.0047626 & 0.00089449 & 0.0037019 & 0.78 & 4.14 & 5.32 \\
\hline Euro Eur & 0.0062326 & 0.0011332 & 0.0070678 & 1.13 & 6.24 & 5.50 \\
\hline China yuan & 0.011215 & 0.001339 & 0.010664 & 0.95 & 7.96 & 8.38 \\
\hline HK dollar & 0.02307 & 0.0030733 & 0.018641 & 0.81 & 6.07 & 7.51 \\
\hline S.Afri Rand & 0.16275 & 0.033763 & 0.16376 & 1.01 & 4.85 & 4.82 \\
\hline Den Kronor & 0.06898 & 0.020616 & 0.048708 & 0.71 & 2.36 & 3.35 \\
\hline Swiss Franc & 0.01249 & 0.0019322 & 0.0085515 & 0.68 & 4.43 & 6.46 \\
\hline Can dollar & 0.0092037 & 0.00016619 & 0.0093686 & 1.02 & 56.37 & 55.38 \\
\hline Mexi Pesos & 0.16201 & 0.018307 & 0.14734 & 0.91 & 8.05 & 8.85 \\
\hline Brazil Real & 0.12089 & 0.013024 & 0.058567 & 0.48 & 4.49 & 9.28 \\
\hline
\end{tabular}


Column 5 of the Table 3 shows that the random walk model beat the standard ARFIMA in 9 out of the 15 exchange rate series. As for the YQ-ARFIMA, it beats the random walk model in all the 15 exchange rate series soundly with the $\mathrm{R} / \mathrm{Q}$ ratio not less than 2 , and one of them goes as high as 99 . The last column of Table 3 shows very clearly that YQ-ARFIMA is very much superior to that of the standard ARFIMA model. The same result is also obtained for the loss function MAPE as shown in Table 4.

Table 4 - Comparing the 8 period forecasting ability of ARFIMA, YQ-ARFIMA and Random Walk in terms of MAPE values for all the 15 exchange rate series.

\begin{tabular}{|c|c|c|c|c|c|c|}
\hline $\begin{array}{l}\text { Name of } \\
\text { the exchange } \\
\text { rate }\end{array}$ & $\begin{array}{l}\text { ARFIMA } \\
\text { (P) }\end{array}$ & $\begin{array}{l}\text { YQ-ARFIMA } \\
\text { (Q) }\end{array}$ & $\begin{array}{l}\text { R.W } \\
\text { (R) }\end{array}$ & $\mathrm{R} / \mathrm{P}$ & $\mathrm{R} / \mathrm{Q}$ & $\mathrm{P} / \mathrm{Q}$ \\
\hline Aus dollar & 0.36808 & 0.0095821 & 0.39356 & 1.07 & 41.07 & 38.41 \\
\hline Mal ringgit & 0.040175 & 0.0018979 & 0.085434 & 2.13 & 45.02 & 21.17 \\
\hline Thai bath & 0.61041 & 0.0052958 & 0.60562 & 0.99 & 114.36 & 115.26 \\
\hline Sin dollar & 1.3670 & 0.052485 & 1.3393 & 0.98 & 25.52 & 26.05 \\
\hline Jap yen & 0.27135 & 0.016082 & 0.29183 & 1.08 & 18.15 & 16.87 \\
\hline UK pound & 0.27819 & 0.051783 & 0.19921 & 0.72 & 3.85 & 5.37 \\
\hline Euro Eur & 0.44234 & 0.081088 & 0.52498 & 1.19 & 6.47 & 5.46 \\
\hline China yuan & 0.50109 & 0.060062 & 0.48873 & 0.98 & 8.14 & 8.34 \\
\hline HK dollar & 0.29629 & 0.033049 & 0.23779 & 0.80 & 7.19 & 8.96 \\
\hline S.Afri Rand & 1.7025 & 0.36122 & 1.7154 & 1.01 & 4.75 & 4.71 \\
\hline Den Kronor & 0.81615 & 0.2556 & 0.55374 & 0.68 & 2.17 & 3.19 \\
\hline Swiss Franc & 0.74407 & 0.11489 & 0.49731 & 0.67 & 4.33 & 6.48 \\
\hline Can dollar & 0.456947 & 0.0082634 & 0.47827 & 1.05 & 57.88 & 55.29 \\
\hline Mexi Pesos & 1.3622 & 0.15169 & 1.2225 & 0.89 & 8.06 & 8.98 \\
\hline Brazil Real & 3.3242 & 0.31612 & 1.3931 & 0.42 & 4.41 & 10.51 \\
\hline
\end{tabular}




\section{Consistency of the YQ-ARFIMA forecasts}

We use the Johansen's cointegration technique and graphical analysis to check the consistency of the YQARFIMA forecasts. Cointegration technique is used because we expect there is a long run relationship for the exchange rates. We use 500 observations to estimate the model, and then, we use the model to make a 200 periods out of sample forecast. We compare these 200 periods forecasts with the actual values by doing unit root tests and then cointegration tests. After doing the experiments, we store up the forecast values. Then we graph the exchange rate with its forecast on the same graph with adjusted similar mean to see whether the two graphs coincide to a reasonable extend or not. After that, we use Johansen's cointegration technique to check for the cointegration rank. We do this experiment for eight exchange rates, Malaysia, Australia, Hong Kong, United Kingdom, South Africa, Canada, Mexico and Brazil. The results of the experiments are shown in Figure 9.

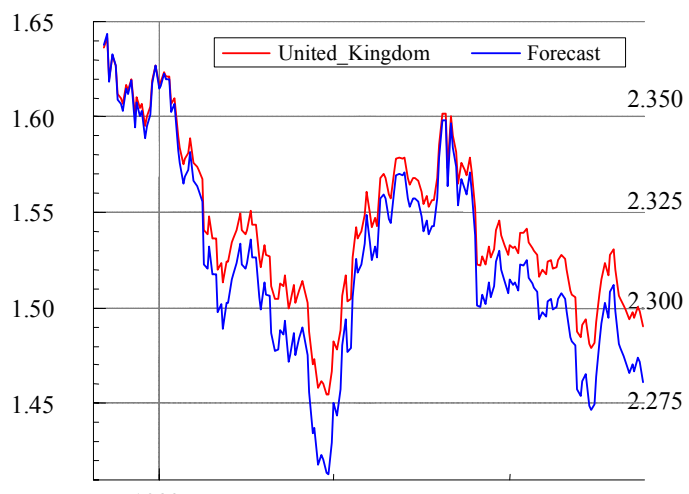

1983

Figure 9(a) - Cointegration graphics for British pound and its forecasts

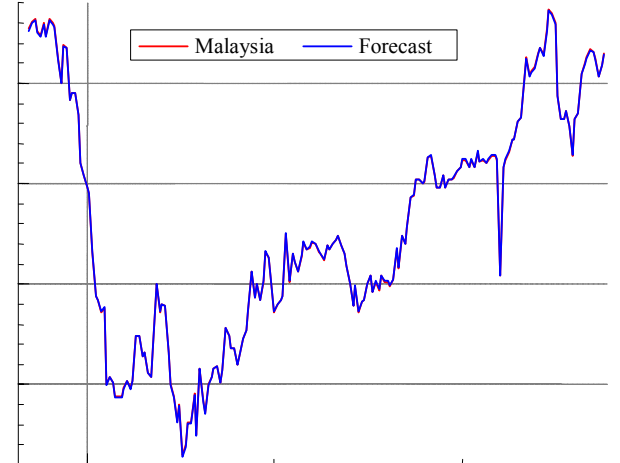

1983

Figure 9(b) - Cointegration graphics for Malaysian ringgit and its forecasts

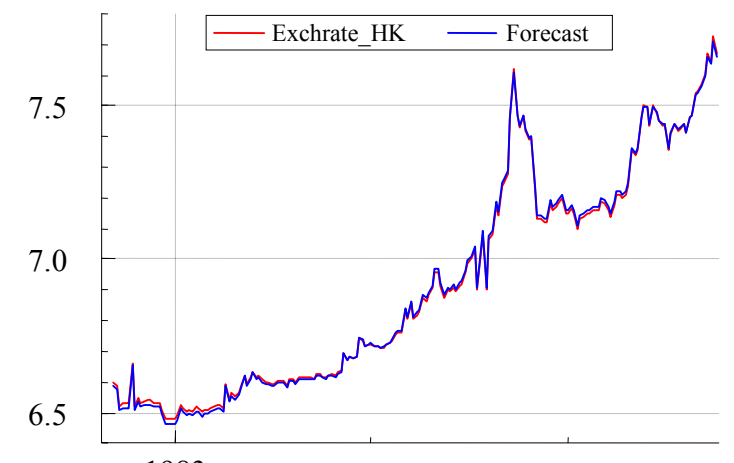

1983
1.00

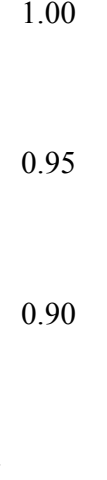

Figure 9(c)-Cointegration graphics for Hong Kong dollar and its forecasts

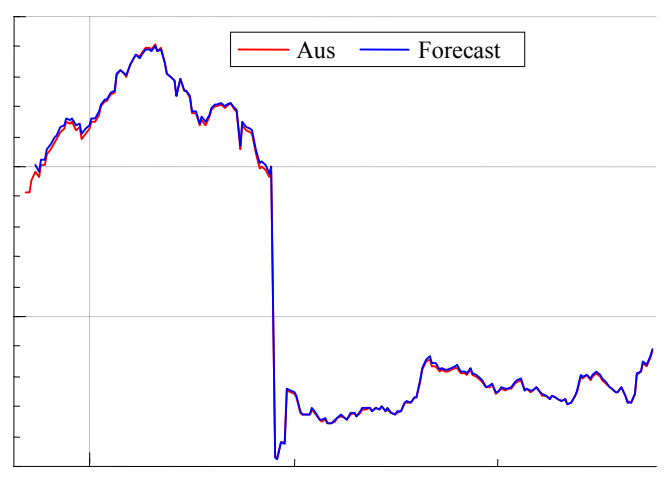

1983

Figure 9(d)- Cointegration graphics for Australian dollar and its forecasts 

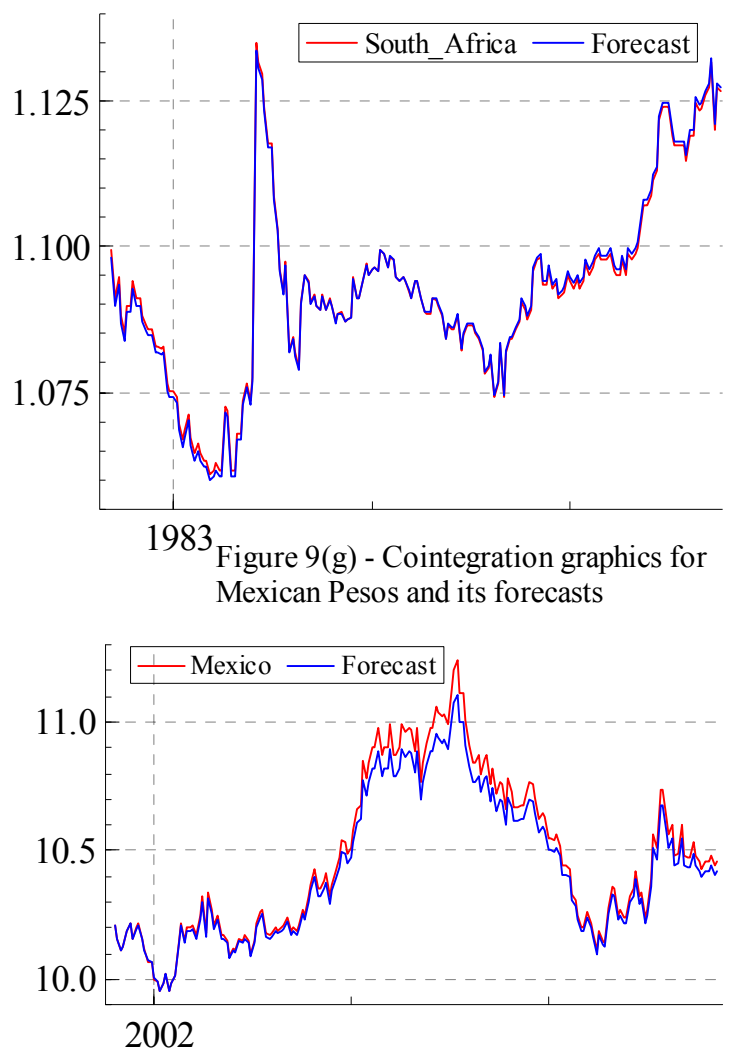

Figure 9(f)- Cointegration graphics for Canadian dollar and its forecasts

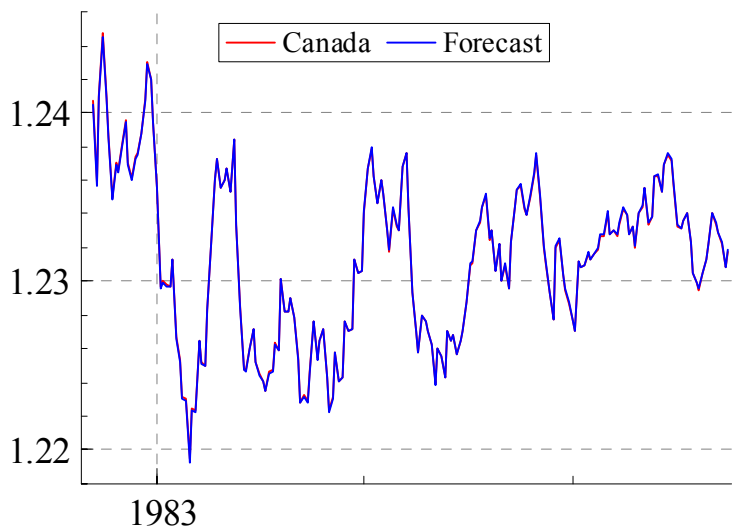

Figure 9(e) - Cointegration graphics for South Africa Rands and its forecasts

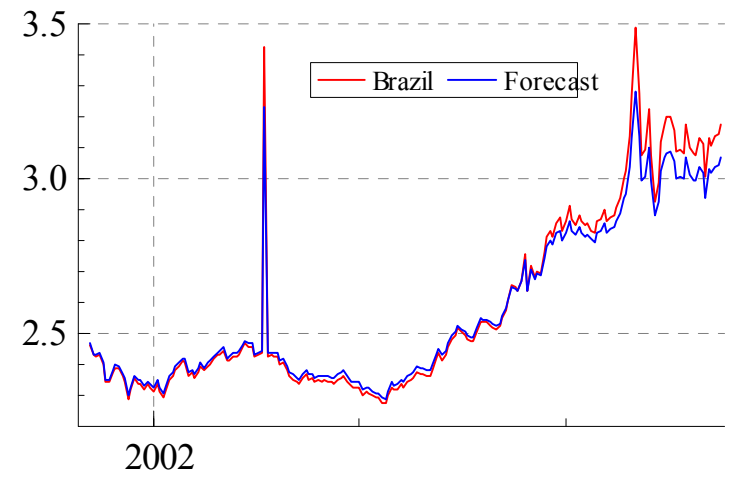

Figure 9(h) - Cointegration graphics for Brazilian Real and its forecasts

Figure 9(a) to Figure 9(h) shows that the forecasts and the relevant actual values are almost coincided except perhaps for British pound, Canadian dollar and Brazilian real where the fitting is not as perfect as the other five cases. Nevertheless, they are considered as good fitting also. Thus, we conclude from the graphical analysis that all the eight exchange rates show that the forecasts by using the YQ-ARFIMA is consistent.

By using the Johansen's cointegration analysis, it is found that all the eight exchange rate series each has a cointegration rank of 1 . This confirms that forecasts by YQ-ARFIMA and the actual values are cointegrated, indicating that the forecasts are consistent.

\section{Conclusion}

By using the loss functions RMSE and MAPE, cointegration consistency in forecasts and impulse response function analysis, we have shown beyond doubt that the YQ-ARFIMA model is very much superior in forecasting ability. In fact as shown in column 6 of Table 3 and Table 4, the YQ-ARFIMA is better than the random walk model more than 10 times for exchange rates from Australia, Malaysia, Singapore, Thailand, Japan and Canada. As for exchange rates from European Union, British pound, Chinese yuan, Hong Kong dollar and 
Mexican Pesos, the number of times that YQ-ARFIMA is better than the random walk model in out of sample forecasting is more than 5, and the rest of the exchange rates is about 4 times. However, we have shown by using impulse response analysis that for exchange rates, Euro, Canadian dollar, South Africa rand and Mexican Pesos are not suitable for analysis by using the YQ-ARFIMA since simultaneous bias is detected in all four exchange rates.

\section{References}

[1] Abuaf, N. \& P. Jourion, Journal of Finance. 45 (1990) 157-174

[2] Andrews, D.W.K, Econometrica. 61 (1993) 821-856.

[3] Andrews, D.W.K. \& Fair, R.C., Review of Economic Studies 55 (1988) 615 - 640

[4] Andrews, D.W.K. and Ploberger, W., Econometrica. 62 (1994) 1383 - 1414.

[5] Ardeni, P.G, \& Lubian, D, Eur.Econ.Rev. 35 (1991) 1035-1955.

[6] Atish, R. G, Anne, M. \& Holger, C.W, Exchange Rate Regimes, Choice \& Consequences. The MIT Press, Massachusetts, 2003.

[7] Bai, J, Econometric Theory. 13 (1997) 551 -563.

[8] Bai, J. \& Perron, P, Econometrica. 66 (1998) 47-78.

[9] Baillie, R.T, Journal of Econometrics. 73 (1996) 5-59.

[10] Baillie, R.T. \& Bollerslev, T, Journal of Econometrics 74 (1989) 3-30.

[11] Balassa, B, Journal of Political Economy. 72 (1964) 584-596.

[12] Barbara Rossi, Are Exchange Rates Really Random Walks? Some Evidence Robust to Parameters Instability. Working Paper, Duke University, 2004.

[13] Beaver, W.H., Lambert, R, \& Morse, D, Journal of accounting and Economics. March (1980) 3-28.

[14] Blen, J.D, Journal International Economics. 33 (1992) 147-166.

[15] Bollerslev, T., Review of Economics and Statistics. 69 (1987) 542-547.

[16] Booth, G.G., Kaen, F.C. \& Koveos, Journal of Monetary Economics. 10 (1982) 407 - 415.

[17] Campbell, Lo \& MacKinlay, Econometrics of Financial Markets. Princeton University Press, Princeton, 1998.

[18] Chen, Nai-Fu \& Richard. R, Journal of Business. 59 (1986) 383-403.

[19] Chen, C. \& Tiao, G.C, Journal of Business \& Economic Statistics. 8 (1990) 83-97.

[20] Cheung, Y. W, Journal of Time Series Analysis 14 (1993) $331-345$.

[21] Cheung, Y, Chinn M. D. \& Antonio G. P, Empirical Exchange Rate Models of the Nineties: Are Any Fit to Survive?. Working Paper. University of California, Santa Cruz, 2003.

[22] Cheung, Y. \& K. Lai, Journal of International Money and Finance 14 (1994) 597 - 615.

[23] Cheung, Y. \& K. Lai, Journal of International Money and Finance. 17 (1998) $597-614$.

[24] Chow, G.C, Econometrica. 28 (1960) 591-603.

[25] Clarida, R.H, L. Sarno, M.P. Taylor, and G. Valente, Journal of International Economics 60 (2003) 61-83.

[26] Clark, P.K, Journal of Economics. 102 (1987) 797-814.

[27] Cochrane, J.H, Journal of Economic Dynamics and Control. 15 (1991) 275-284.

[28] Cochrane, John H, New Facts in Finance. Working Paper, University of Chicago. 1999.

[29] Dickey, D.A. and Fuller W.A, Journal of the American Statistical Association. 74 (1979) 427-431.

[30] Diebold, F.X, Elements of Forecasting, South-Western Publishing, Cincinnati, 1998.

[31] Diebold, F.X. \& Lopez, J, Modeling volatility Dynamics in Kevin Hoover (Eds.), Macroeconometrics: Developments, Tensions and Prospects. Kluwer Academic Press, Boston, 1995, pp. 427 - 472.

[32] Diebold, F.X., \& Rudebusch, G.D, Journal of Monetary Economics. 24 (1989) 189-209.

[33] Ding, Z, Granger, C.W.J. \& Engle, R.F, Journal of Empirical Finance. 1 (1993) 83-106.

[34] Drost, F.C. \& Nijman, T.E, Econometrica. 61 (1993) 909-927.

[35] Duan, J.C, Conditionally fat-tailed distributions and the volatility smile in options. HongKong University of Science and Technology working paper, 1999. 
[36] Edison, H.J, Journal of Money, Credit and Banking. 19 (1987) 376-387.

[37] Edison, H.J, \& Klovland, J.T, Journal of Applied Econometrics. 2 (1987) 309-333.

[38] Elliott, G, Rothenberg, T.J. and Stock J.H, Econometrica. 64 (1996) 813-836.

[39] Engel, C, and Chang, J.K, The Long Run U.S./U.K. Real Exchange Rate. Working Paper. University of Washington, 2000.

[40] Engle, R.F. and C.W.J. Granger, Econometrica. 55 (1987) 251-276.

[41] Engel, C, \& J.D. Hamilton, American Economic Review. 80 (1990) 689-713.

[42] Engle, R.F, Hendry, D.F, and Richard, J, Econometrica, 51 (1983) 277-304.

[43] Engle, R.F, \& Patton, A, What good is a volitily model. Manusript at Stern, NYU, 2000.

[44] Fama, E.F, Journal of Business. 38 (1965) 34-105.

[45] Fama, E.F, \& French, K.R, Journal of Financial Economics. 25 (1988) 23-49.

[46] Fama, E.F, \& Gibbons, M.R, Journal of Monetary Economics. 9 (1982) 297-323.

[47] Franses , P. H, Time Series Models for Business and Economic Forecasting. Cambridge University Press, Cambridge, 1998.

[48] Franses , P. H, \& Dijk D.V, Non-linear time series models in empirical finance. Cambridge University Press, Edinburgh, 2000.

[49] Fumio Hayashi, Econometrics. Princeton University Press, Princeton, 2000.

[50] Geweke, J. \& S. Porter - Hudak, Journal of Time Series Analysis. 4 (1983) 221 - 238.

[51] Gordin, M. I, Soviet Math. Dokl. 10 (1969) 1174-1176.

[52] Gonzalo, J \& Dolado, J.J, Cointegration. Working Paper. Universidad Carlos III de Madrid, 1999.

[53] Gradshteyn, I. R., and Ryzhik, I. M, Table of Integrals, Series, and Produces. Academic Press. New York, 1980.

[54] Granger, C.W.J. \& Ding, Z, Journal of Econometrics. 73 (1996) 61-78.

[55] Granger, C.W.J, \& Hyung, N, Occasional Structural Breaks and Long Memory. Working Paper 99: UCSD, 1998.

[56] Granger, C.W.J. \& Joyeux, R, Journal of Time Series Analysis. 1 (1980) 15 - 39

[57] Granger C.W.J, \& Terasvirta, T, Economics Letters. 62 (1999) 161-165.

[58] Greene, W.H, Econometric Analysis. Prentice Hall International Edition, 2003.

[59] Grilli, Vittorio \& Kaminsky, G, Journal of Monetary Economics. 27 (1991) 191-212.

[60] Hall, A.D. and McAleer, M, Journal of Business \& Economic Statistics. 7 (1989) 95-106.

[61] Hamilton, J.D, Journal of Econometrics. 73 (1989) $61-77$.

[62] Hamilton, J.D, Time Series Analysis. Princeton University Press, Princeton, 1994.

[63] Hamilton, J.D, State space models. Handbook of Econometrics. 4 (1994) 3041-3068.

[64] Hansen, B.E, Journal of Econometrics. 97 (2000) 93 - 115.

[65] Hansen, H., \& Johansen, S, Recursive estimation in cointegrated VAR models. Working Paper: Institute of Mathematical Statistics, University of Copenhagen, 1993.

[66] Hansen, L.P, Econometrica. 50 (1992) 1029-1054.

[67] Hansen, R,P, An unbiased and powerful test for superior predictive ability. Working Paper 01-06, Brown University, 2001.

[68] Harvey, A.C, \& Jaeger, A.J, Journal of Applied Econometrics 8 (1993) 231 - 247.

[69] Harvey, A.C, American Statistical Association. 3 (1985) 216 - 227.

[70] Harvey, A.C, \& Phillips, G.D.A, Journal of the American Statistical Association. 79 (1984) 125 - 131.

[71] Harvey, A.C. \& Scott, Economic Journal. 104 (1994) 1324-1345.

[72] Harvey A.C. \& Todd, P.H.J, Journal of Business and Economic Statistics. 1 (1983) 299 - 307.

[73] Henry, D.F, and Neale, A.J, Monte carlo experimentation using PC-NAÏVE, In Fomby, T. and Rhodes, G.F, Advances in Econometrics, Vol 6, Jai Press Inc. Greenwich Connecticut, 1987, pp. 91-125.

[74] Hosking, J.R.M, Biometrika. 68 (1981) $165-176$.

[75] Hyung, N \& Granger, C.W.J, Occasional Structural Breaks and Long Memory. Working Paper 99: UCSD, 1998. 
[76] Kalman, R.E, A new approach to Linear Filtering and Prediction Problems. Proceeding of the First symposium of Engineering applications of Random Function Theory and Probability, John Wiley \& sons, Inc. New York, 1960, pp. 270-388.

[77] Kilian, L., \& Taylor, M. P., Journal of International Economics. 14 (2003) 491-510

[78] Kim, C.J, \& Nelson, C.R, State space models with regime switching. The MIT Press, Massachusetts, 1999.

[79] Kim, C.J., Nelson, C.R. \& Startz, R, Journal of Empirical finance. 5 (June 1998), 132 -154.

[80] Kim, Y, Journal of Money, Credit and Banking. 22 (1990) 491-503.

[81] Kuan-Pin Lin, Computational Econometrics, ETEXT Text Book Publisher, Los Angeles, 2001.

[82] Lo, A.W, Econometric Theory 41 (1988) 231-247.

[83] Lo, A.W, Econometrica. 59 (1991) 1279 - 1313.

[84] Lothian, J. R. and Taylor, M. P, Journal of Political Economy, 104 (1996) 488-509.

[85] Maddala, G.S. \& Kim, I.M, Unit roots, cointegration and structural change. Cambridge University Press, Cambridge, 1998.

[86] McCracken, M.W. \& Sapp, S, Evaluating the Predictability of Exchange Rates using Long Horizon Regressions: Mind Your p's and q's. Working Paper, University of Western Ontario, 2004.

[87] Meese, R.A. \& Singleton, K.J, Journal of Finance, 37 (1982) 1029-1035.

[88] Meese, R.A. \& Rodoff, K, Journal of International Economics, 14 (1983), 3-24.

[89] Mills, T.C, The Econometic Modelling of Financial Time Series, $2^{\text {nd }}$ Edition. Cambridge University Press, Edinburgh, 2000.

[90] Myers, R.H. and Milton, J.S., A first course in the theory of linear statistical models. PWS-KENT Publishing Company, 1991.

[91] Ng, S , \& Perron, P, Journal of the American Statistic Association, 90 (1994) 268-281

[92] Nelson, C.R. \& Kim, C.J, Journal of Empirical finance. 5 (1998), 131-154

[93] Nelson, C.R. \& Plosser, C.I, Journal of Monetary Economics 10 (1982), 309 - 315.

[94] O. Connell P.G.J, Journal of International Economics. 44 (1998) 1-19.

[95] Pagan, A.R. and Schwert, G.W, Journal of Econometrics. 45 (1990) 267-290.

[96] Perron, P., and S. Ng, Review of Economic Studies. 63 (1996) 435 - 463.

[97] Quandt, R, Journal of the American Statistical Association. 55 (1960) 324 - 330.

[98] Robinson, P.M, Annals of Statistics 23 (1995) 1630 - 1661.

[99] Robinson, P.M \& Henry, M, Econometric Theory 15 (1999) 299 - 336.

[100] Rogoff, K, Journal of Economic Literature. 34 (1996) 647- 668.

[101] Ryden, T, Terasvirta, T, and Asbrink, S, Journal of Applied Econometrics. 13 (1998) 217-244.

[102] Schinasi,G.J, \& P.A.V.B. Swamy, Journal of International Money and Finance. 8 (1989) 375-390.

[103] Schwert, G.W, Journal of finance. 44 (1989) 1115-1153.

[104] Sowell, F, Econometrica. 58 (1990), 495 - 506.

[105] Stock, J. H, Journal of Econometrics 63 (1994) $105-131$.

[106] Stock, J.H.. \& Watson, M.H, Intoduction to Econometrics. Pearson Education, Inc. New Jersey, 2003.

[107] Stock, J.H.. \& Watson, M.H, Journal of Business and Economic Statistics. 14 (1996) 11-30.

[108] Swanson, N, Forecasting Using First Available Versus Fully Revised Economic Time Series Data. Working paper, Pennsylvania State University, 1995.

[109] Taylor, S, Modeling Financial Time Series. Wiley and Sons, New York, NY. 1986.

[110] Watson, M. W, Journal of Econometrics. 41 (1986) $65-89$.

[111] White, H, Econometrica. 48 (1980) 421-448.

[112] White, H, Estimation, Inference and Specification Analysis. Working Paper. 94: UCSD, 1984.

[113] William H. Greene, Econometric Analysis, $5^{\text {th }}$ Edition. Pearson Education, Inc. New Jersey, 2003.

[114] Zhou, B, Journal of Business and Economic Statistics. 14 (1996) 45-52. 